\title{
Overview on cold cement bitumen emulsion asphalt
}

\author{
Xing Fang ${ }^{a, b *}$, Alvaro Garcia-Hernandez ${ }^{c}$, Pietro Lura ${ }^{a, b}$ \\ ${ }^{a}$ Empa, Swiss Federal Laboratories for Materials Science and Technology, $\mathrm{CH}-8600$ Dübendorf, Switzerland \\ b Institute for Building Materials, ETH Zurich, Switzerland \\ c University of Nottingham, Div. of Infrastructure and Geomatics, Faculty of Engineering, Univ. of Nottingham, University Park, NG7 2RD, \\ United Kingdom
}

Received: 15 December 2016 / Accepted: 22 December 2016 / Published online: 29 December 2016

(C) The Author(s) 2016. This article is published with open access.

\begin{abstract}
Cold mix asphalt, a promising substitute for conventional hot mix asphalt, is manufactured at ambient temperature using bitumen emulsion as binder. To improve its strength and durability, cement is often added to the mixture. This review (1) presents an overview about advances in cold mix asphalt modified with cementitious materials, often called CBEA (cement bitumen emulsion asphalt), (2) illustrates advantages and disadvantages of CBEA and (3) gives recommendations to produce homogenous CBEA mixtures.
\end{abstract}

Keywords: Cold mix asphalt; Cementitious materials; Cement bitumen emulsion asphalt

\section{Introduction}

Hot mix asphalt (HMA) is generally made by mixing preheated mineral aggregates (at $180-250^{\circ} \mathrm{C}$ ), bitumen binder that is usually generated from crude petroleum (at $160^{\circ} \mathrm{C}$ ), filler and other additives. Since the working temperature is relatively high, large amounts of fuel are required for heating up the aggregates and the bitumen. $A$ recent survey shows that about 7.6-9.7 I of fuel are burned to produce 1 ton of HMA [1-3], consuming $275 \mathrm{MJ}$ energy $[4,5]$ and contributing $15 \%$ to the total cost of HMA manufacture [3]. From the oil crisis in the 1970s and the Kyoto Protocol in 1997, researchers paid increasing attention to the environmental impact and the sustainability of asphalt. Low emission asphalt (LEA) has attracted considerable attention because of its low environmental impact and cost-effectiveness [6]. In particular, warm-mix asphalt, which is produced at temperatures around 115$140^{\circ} \mathrm{C}$, was thought to be a promising substitute for HMA [2]. However, the amounts of fuel saved by using warm-mix asphalt are typically only in the range of $20-35 \%$ [2].

Researchers in the asphalt industry are constantly looking for ways to lower the energy consumption, the greenhouse gas emission and to improve the cost-effectiveness. Cold mix asphalt is the result of studies in this direction over the last few decades. Cold mix asphalt usually refers to an asphalt mixture obtained by mixing bitumen emulsion, aggregates and filler at ambient temperature [7]. By using cold mix asphalt, energy savings of $95 \%$ compared to HMA manufacturing can be achieved $[4,5,8]$.

The disadvantages of cold mix asphalt are also obvious. Because water needs to evaporate from bitumen emulsion in order for the bitumen to develop adhesion with the aggregates, cold mix asphalt may need several weeks to reach its full strength [9]. This can result in inferior early strength and high porosity when compared with conventional hot mix asphalt [10-12]. Additionally, because of the water in the mixture, the moisture damage potential and the durability are of concern $[13,14]$. As a consequence, cold mix asphalt has rarely been used as structural layer for heavy-duty pavements $[15,16]$.

In order to improve the early performance of cold mix asphalt, Ordinary Portland Cement (OPC) can be added to the mixture: $1-2 \%$ OPC (by mass) significantly improve the early mechanical properties $[17,18]$ and the fully-cured material may acquire mechanical properties comparable or even better than those of an equivalent HMA $[10,19,20]$. Research on these composite materials, also called CAEC (Cement-Asphalt Emulsion Composite) [21,22], CBEM (cold bituminous emulsion mixture) [9,12], C-ETM (CementEmulsion Treated Mixture) [23] or CBTM (cement-bitumen treated material) [24], started in the 1970s. In all these materials, the primary binder is bitumen while cement is used as an admixture. In the present paper this composite will be called CBEA, Cement Bitumen Emulsion asphalt. Extensive studies have also been made on a related

* Corresponding author: Xing Fang, E-mail: xing.fang@empa.ch, Tel.: (+41) 0587656508 
composite called cement asphalt mortar (CA mortar), which is used in particular as an interlayer between concrete roadbed and slab track for high speed railway $[25,26]$. In CA mortar, cement (present in higher amount than in CBEA) is the main binder and bitumen emulsion is an additive that improves the flexibility of the mortar [26-31].

In CBEA, cement improves the strength and durability of cold mix asphalt and reduces the strength acquisition time, while at the same time maintaining all main advantages of cold mix asphalt, such as lower energy consumption, lower gaseous emissions (potentially harmful for health and environment) and lower manufacture cost [32]. In fact, already small amount of OPC are able to increase the strength of CBEA at early ages [33], particularly in the first few days, which enabled CBEA to acquire comparable loadbearing capabilities with HMA. Meanwhile, due to cement addition, CBEA shares characteristics of both cement and asphalt concrete [33]. In particular, compared with conventional HMA, CBEA possesses higher deformation resistance and lower temperature susceptibility [23]. According to recent studies, cement addition is almost indispensable for asphalt mixtures in which bitumen emulsion is used, such as cold mix asphalt and cold recycling asphalt [34-37].

This paper presents an overview on advances in CBEA in the past few decades. Its main objectives are to outline the development of CBEA, to address some issues that appeared in other studies and to briefly introduce the main properties of CBEA.

\section{How to produce CBEA?}

\subsection{Bitumen emulsion}

The most important parameter to produce homogenous CBEA mixtures is the mixing stability of the bitumen emulsion. According to Salomon [32], in most cases medium setting and slow setting bitumen emulsions are used, while rapid setting bitumen emulsions are not recommended. This is because rapid setting bitumen emulsion flocculates and coalesces rapidly in the presence of fine aggregates and filler with relatively high specific surface area, causing balling of bitumen and insufficient coating of aggregates [38]. While some researchers claimed that positively-charged cationic emulsion may develop stronger adhesion bond with negatively-charged acidic aggregates containing high amount of silica [22,39], this has not been confirmed experimentally.

The main concern when using cationic emulsion is that the $\mathrm{pH}$ of the mixture may rapidly increase, even reaching a value around 13 . Cement addition neutralizes the acids in cationic emulsions, causing the destabilization of the emulsion [32]. On the other hand, the main concern when using anionic emulsion is the effect of multivalent ions, especially $\mathrm{Ca}^{2+}$, that are released by cement upon contact with water. It has recently been confirmed that $\mathrm{Ca}^{2+}$ ions react with anionic emulsifiers and destabilize bitumen emulsion [40].
An appropriate bitumen emulsion selection should guarantee that the emulsion can maintain its stability before compaction. To this end, a mixing stability test is highly recommended. However, no standardized test for mixing stability in the presence of cement exists. In reference [41], a rheology test to quantitatively describe the mixing stability of bitumen emulsion is introduced. Fig. 1 shows an example of gelation time of various cement-bitumen emulsion blends using a Brookfield viscometer to measure the viscosity of cement-bitumen emulsion blends over time. A similar approach has also been proposed by Ouyang et al. [42-44]. In practice, it may take about half an hour to transport asphalt mixtures from the mixing plant to the construction site. As a consequence, the gelation time of bitumen emulsion should be 30 min or longer.

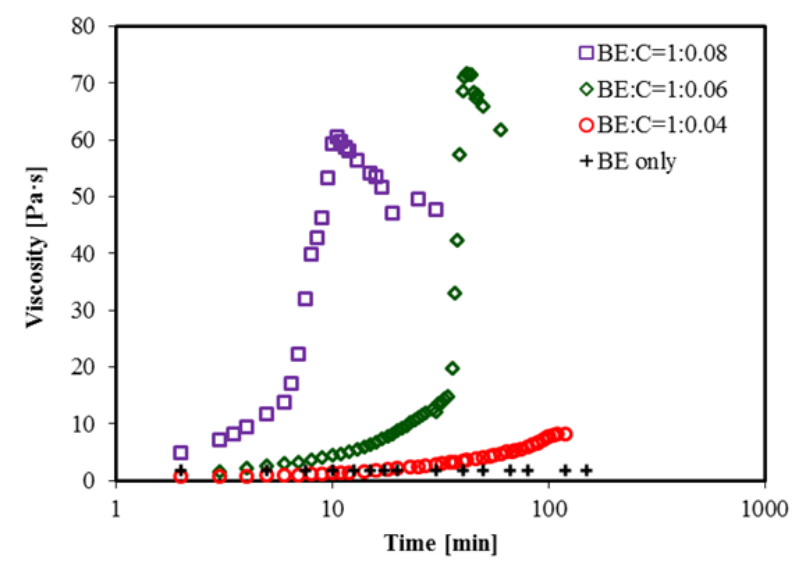

Figure 1. An example of gelation time of various cement-bitumen emulsion blends (adapted from [41], the legend shows bitumen emulsion to cement ratio, $B E$ refers to bitumen emulsion and $C$ refers to cement, $B E$ only refers to reference sample without cement).

\subsection{Aggregates, cement and gradation}

It is generally recognized that CBEA does not require any specific type of aggregates or gradation. In general, aggregates suitable for HMA are also suitable for CBEA. Crushed limestone aggregates are considered to be the most appropriate because their porous texture can absorb water from the emulsion, which benefits the strength development [32]. In most cases, a dense gradation is used $[19,20,33]$, while in some cases an open gradation (preferentially for porous asphalt) has been used (e.g. [34]).

OPC is generally used in CBEA because it is a commonly-used cement throughout the world. In addition, the use of rapidhardening cements has been investigated and it has been found that the early strength of CBEA mixture can be significantly increased [7]. In addition, rapid-hardening cements such as calcium sulfoaluminate and calcium aluminate cements, can bind more water and reduce the $\mathrm{CO}_{2}$ footprint compared with OPC [7].

\subsection{Bitumen emulsion and cement content}

Mixture design methods that are used for hot mix asphalt are also applied to CBEA. Depending on the gradation, HMA 
usually contains $4-6 \%$ bitumen by mass of dry aggregates. Once the target bitumen content is determined, bitumen emulsion content can be calculated. Bitumen emulsions produced for pavement applications generally contain $60 \%$ bitumen. For example, if $6 \%$ bitumen is needed, $10 \%$ bitumen emulsion needs to be added.

The cement content in CBEA ranges from 1 to $6 \%$ $[19,20,33,45]$. Because cement is used as a secondary binder, the strength of CBEA increases with cement content. However, cement content is normally minimised because cement addition increases (1) the brittleness of CBEA and (2) its cost and $\mathrm{CO}_{2}$ footprint. Studies have shown that $2 \%$ cement addition results in equivalent strength with HMA after about 2 months-curing [19]. From the environmental point of view, adding $2 \%$ cement will result in the same $\mathrm{CO}_{2}$ emission as HMA [46] (details are discussed in section 3.1). Taking all these factors into consideration, $1-2 \%$ cement is normally recommended for producing CBEA [46].

\subsection{Mixing procedures and curing conditions}

Because CBEA can be produced at ambient temperature, it is easier and safer to handle than HMA. In laboratory, the raw materials are added into the mixer and mixed in this order: first the coarse aggregates, then the bitumen emulsion, and finally, the sand, the filler and the cement. In some cases, additional water is added $[19,20]$. The purpose of adding additional water is to lubricate the aggregates.

Curing conditions are a key factor for strength development in early ages. In the laboratory, the temperature and the relative humidity can be precisely controlled [20]. Our previous study has shown that water provided by bitumen emulsion is more than enough for cement hydration $[7,47]$. Lower relative humidity is recommended because it accelerates water evaporation and the strength gain of CBEA. At the construction site, warm, dry and sunny weather is preferred for paving with CBEA due to higher evaporation rate. At early ages, rain should be avoided [11].

\section{Properties of CBEA}

\subsection{Energy usage and $\mathrm{CO}_{2}$ emissions of CBEA}

Chappat et al. have studied the energy usage and $\mathrm{CO}_{2}$ emissions of different asphalt mixtures [4]. According to this research, manufacture 1 ton of conventional HMA consumes about $680 \mathrm{MJ}$ [4]. Cold mix asphalt and cold in-situ recycling consume only $2 / 3$ and $1 / 5$ of that in $\mathrm{HMA}$, respectively. However, if cement is added to cold mix asphalt, the $\mathrm{CO}_{2}$ emissions increase dramatically, since OPC production results in approximately $0.87 \mathrm{t}$ of $\mathrm{CO}_{2}$ (both from combustion of fossil fuels and from decarbonization of limestone) for every ton of cement produced [48]. According to [4], the production of 1 ton of HMA and of cold mix asphalt results in the emission of 53.6 and $36.1 \mathrm{~kg} \mathrm{CO}$, respectively.

In the case of CBEA, the addition of $2 \%$ cement in cold mix asphalt will result in the same $\mathrm{CO}_{2}$ emissions as $\mathrm{HMA}$, i.e. $53.7 \mathrm{~kg} / \mathrm{t}$. The corresponding energy consumption is $546.3 \mathrm{MJ} / \mathrm{t}$, which is $80 \%$ of that in HMA.

\subsection{Strength development of CBEA}

Recent research has shown that cement increases the early strength of CBEA by acting as a binder $[7,11]$. For this reason, both cement hydration and emulsion breaking contribute to strength development of CBEA. Any factor that affects cement hydration and emulsion breaking also affects strength development of CBEA. For example: water to cement ratio $(w / c)$, curing condition including temperature and relative humidity, additives etc.

The strength of CBEA (depending on the test method, the strength of CBEA is generally reflected by either the Marshall stability or the stiffness modulus [19]; in the present paper, we indicate both as "strength") increases with curing time and cement addition level. Fig. 2 shows typical experimental results of strength development (the strength is indicated by the stiffness modulus in Fig. 2). The strength of CBEA mixtures increases over time because of cement hydration and emulsion breaking. On the other hand, an increase in cement addition level can significantly increase the strength of CBEA. Compared with HMA, CBEA shows comparable or even higher strength after a few days of curing. For example, when $1 \%$ cement is added, CBEA shows higher strength after about 1 month, while this time is shortened to about 1 week when $2 \%$ cement is added (Fig. 2). In order to shorten the curing time and to minimize cement addition at the same time, $2 \%$ OPC is recommended for CBEA. In addition, rapid hardening cement (for instance, calcium aluminate and calcium sulfoaluminate cement) can be added to increase the early strength and shorten the curing time [7].

Curing condition such as temperature, relative humidity and sample size should be also considered when designing. For example, Garcia et al. [20] have reported that lower relative humidity could shorten the curing time. Although CBEA mixtures show good performance in the laboratory, improper correlation between laboratory and field results may still happen. However, this correlation has not been studied in detail so far.

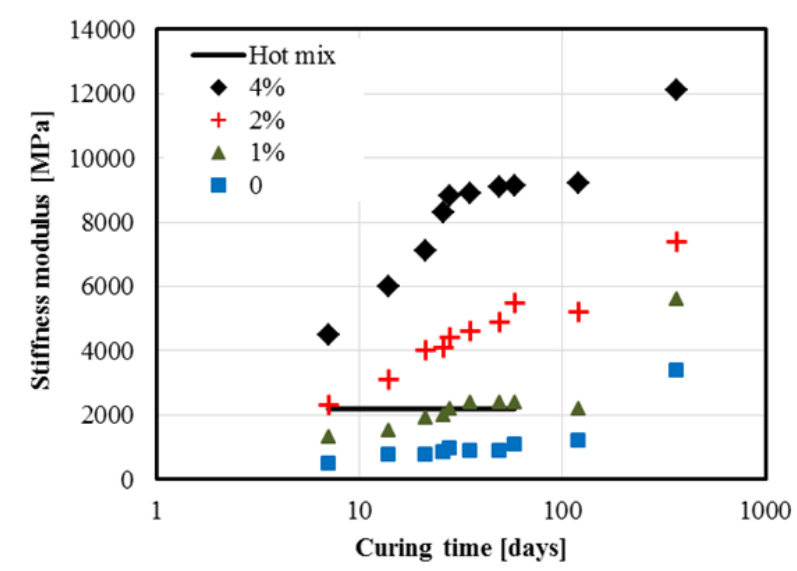

Figure 2. Strength development of CBEA mixture over time (adapted from [19], legend in the figure shows cement addition level, data obtained by indirect tensile test). 


\subsection{Bitumen emulsion breaking in the presence of cement and filler}

Fig. 3a-d shows the effect of filler and cement on the stability of bitumen emulsion droplets. When filler was added, bitumen droplets were still mostly discrete, see Fig. 3a and $3 \mathrm{~b}$ no substantial interaction between filler particles and bitumen droplets was observed. However, the addition of cement caused the formation of much larger interconnected flocs (see Fig. 3c). In addition, part of the bitumen droplets merged together and larger bitumen droplets were generally observed (Fig. 3d). Furthermore, some bitumen droplets were adsorbed on the surface of cement particles (Fig. 3d).Cement destabilizes bitumen emulsion due to two main reasons: $\mathrm{pH}$ change and $\mathrm{Ca}^{2+}$ ions released by the dissolution of cement. Due to the high $\mathrm{pH}$ caused by cement hydration, cationic emulsion can break immediately after cement addition (rapid setting cationic bitumen emulsions). Therefore, anionic bitumen emulsions may be recommended to produce CBEA mixtures. However, the $\mathrm{Ca}^{2+}$ ions released by the dissolution of cement can react with some anionic emulsifier molecules such as rosin [40].

\subsection{Cement hydration}

Because cement is used as a secondary binder, cement hydration is of particular importance to CBEA. Cement hydration directly affects the strength at early ages and elastic modulus of CBEA after curing. An earlier study confirmed that water for cement hydration supplied by bitumen emulsion is theoretically more than enough to hydrate completely the amount of cement used in CBEA [7]. However, researchers have been often concerned that cement hydration may be hindered by bitumen emulsion because bitumen may form a membrane on the surface of cement particles. Although this viewpoint is not comprehensively supported by experimental results, it has been repeated several times $[35,49,50]$. In $[7,26,45]$ it has been observed that bitumen emulsion has no substantial influence on the hydration of cement beyond the first few hours of hydration, see Fig. 4.
It should be noted that in [26], bitumen emulsion was added as into cement slurry as an additive and all mixtures were prepared at $w / c$ of 0.45 . In the case of references [7, 45], cement was added into bitumen emulsion as an additive and the w/c was much higher (1.0-3.14).

\subsection{Microstructure}

Fig. 5 shows a cross section of cured CBEA with approximate diameter of $5 \mathrm{~mm}$ [46]. In this sample, aggregates larger than $2.8 \mathrm{~mm}$ were not used. Some cracks in aggregates are observed, which may be caused by sample preparation. As reported by Poulikakos et al. [51], micro-cracks in aggregates can be observed in HMA samples prepared by gyratory compactor, but not in field-compacted samples. As shown in Fig. 5, a large amount of air voids are also evident. Pouliot et al. [27] reported that, depending on bitumen amount, the air void content in CBEA can be as high as $10 \%$ after $28 \mathrm{~d}$, which is much higher than HMA (4\%) [52]. This suggests that CBEA may suffer from water damage, and consequently result in debonding due to the large amount of air voids [46].

The main problems of CBEA are the homogeneity and the strength [46], which are closely correlated. Improving the homogeneity of the mixture can significantly increase the strength of CBEA [46]. This can be achieved by improving the mixing stability of the bitumen emulsion [47]. With this purpose, one can use a nonreactive emulsifier or surfaceactive particles to produce bitumen emulsion [46]. The early strength can be improved by adding rapid-hardening cements as shown in [7]. However, the effect of rapid hardening cements on other aspects of performance (for example, on the stiffness of the material) is not clear at this moment [46]. For CBEA mixture design, if the cement content is fixed, one can obtain the optimum mixture by adjusting the mixing stability of the bitumen emulsion [46]. For example, one can change the type or the content of emulsifier [47]. In the case when the bitumen emulsion (emulsion type and amount) cannot be changed, one can optimize the CBEA mixture by adjusting cement type, cement content or by adding additives such as emulsifiers [46].

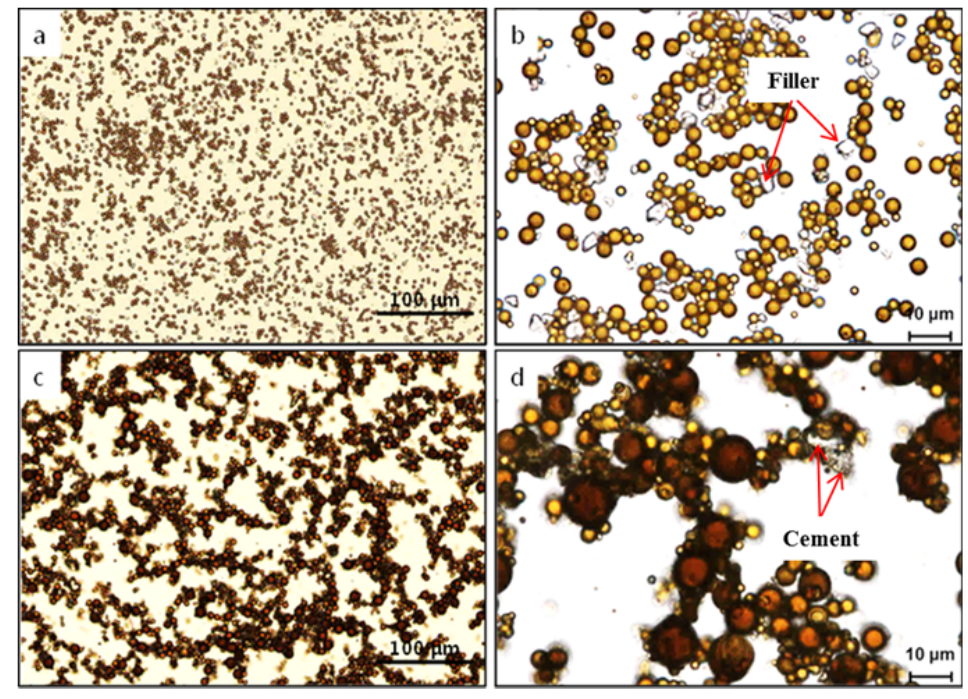

Figure 3. Diluted bitumen emulsion in the presence of filler (a, b) and cement (c, d) (adapted from [41]). 

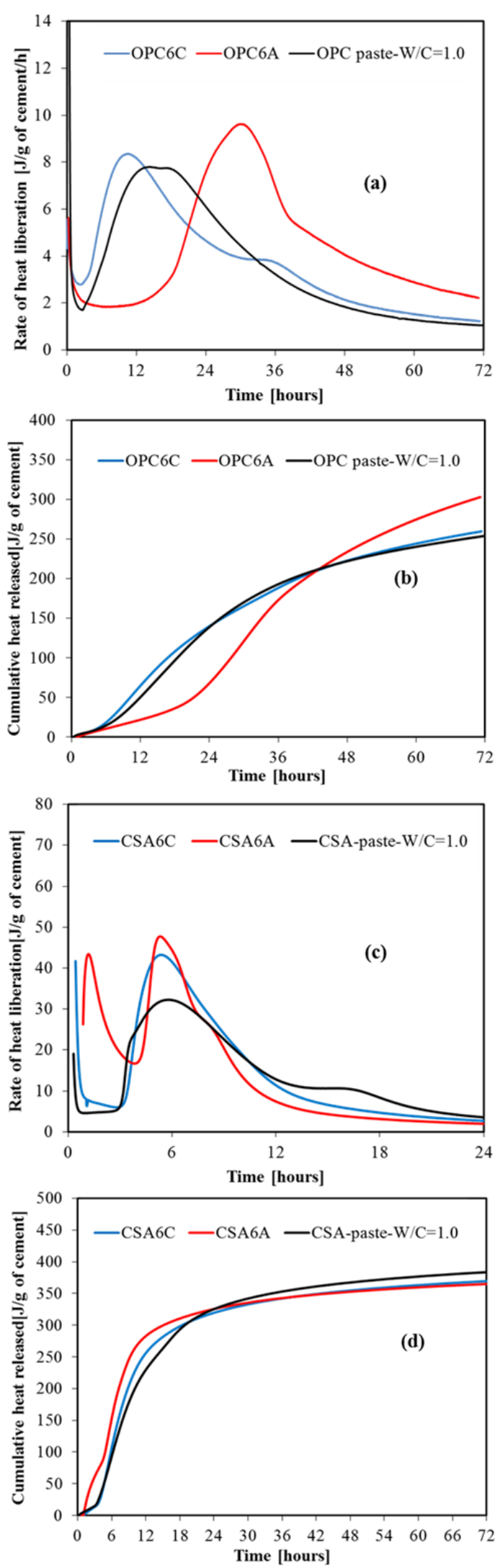

Figure 4. Calorimetry test results of CBEA mixtures: cationic emulsion with $6 \%$ cement (blue), anionic emulsion with and $6 \%$ cement (red) and cement paste with w/c 1.0 (black) (modified from [46], Fig. $4 a$ and $4 b$ show test results of OPC; Fig. $4 c$ and $4 d$ show test results of CSA cement). The evolution of the cumulative heat mirrors the evolution of the degree of hydration of the cement.



Figure 5. Micro CT image of cured CBEA mixture[46].

\section{Conclusions}

Homogenous CBEA mixtures can be produced by using 1-2\% cement, appropriate slow-setting bitumen emulsions. CBEA mixtures show advantages over HMA in terms of energy usage (up to about $5 \%$ cement addition) and $\mathrm{CO}_{2}$ emissions (up to about $2 \%$ cement addition). Although CBEA mixtures show a much slower strength gain (within a couple of weeks) than HMA, rapid hardening cement can be used to increase the early strength and shorten the curing time (in 24 hours). Cement addition is critical for strength development of CBEA because on one hand, cement accelerates emulsion breaking. On the other hand, cement acts as a secondary binder after hydration. While some progress has been made to improve the mixing stability of bitumen emulsion in order to obtain a homogenous CBEA mixture, the moisture susceptibility and other properties connected to durability in the field need further study. In addition, although CBEA mixtures show good performance in the laboratory, improper correlation between laboratory and field results may still happen. Field investigation and full-scale field trials can be conducted to study the field performance of CBEA.

\section{Acknowledgements}

The first author was financed by a scholarship from the China Scholarship Council.

\section{References}

[1] J. Skolnik, M. Brooks, J. Oman, REPORT 744 Fuel Usage Factors in Highway and Bridge Construction, 2013.

[2] J. D'Angelo et al., Warm-Mix asphalt : European Practice, 2008.

[3] E. J. Sullivan, A. Moss, Paving Cost Comparisons : Warm-Mix Asphalt Versus Concrete, PCA Mark Intell, 2014.

[4] M. Chappat, J. Bilal, The environmental road of the future: energy consumption and greenhouse gas emission, 2003.

[5] J. Chehovits, L. Galehouse, Energy usage and greenhouse gas emissions of pavement preservation processes for asphalt concrete pavements, Proc. 1st International Conference on Pavement Preservation, 2010, 27-42. 
[6] B. Pidwerbesky, A. Beuyenberg, J. De Bono, Low Emissions Asphalt Experience to date, Proc. 13th Int Flexible Pavements Conference, 2009.

[7] X. Fang, A. Garcia, F. Winnefeld, M. N. Partl, P. Lura, Impact of rapidhardening cements on mechanical properties of cement bitumen emulsion asphalt, Mater Struct (2016) 49: 487-498. https://doi.org/10.1617/s11527-014-0512-3

[8] S. Goyer, M. Dauvergne, L. Wendling, J-C. Fabre, C. de la Roche, V. Gaudefroy, Environmental evaluation of gravel emulsion, Proc. of Life Cycle Assessment and Construction International Congress, 2012, 170-178.

[9] H. Al Nageim, S. F. Al-Busaltan, W. Atherton, G. Sharples, A comparative study for improving the mechanical properties of cold bituminous emulsion mixtures with cement and waste materials, Constr Build Mater (2012) 36: 743-748. https://doi.org/10.1016/j.conbuildmat.2012.06.032

[10] S. Al-Busaltan, H. Al Nageim, W. Atherton, G. Sharples, Mechanical Properties of an Upgrading Cold Mix Asphalt Using Waste Materials, J Mater Civ Eng (2012) 24: 1484-1491. https://doi.org/10.1061/(ASCE)MT.1943-5533.0000540

[11] D. Needham, Developments in bitumen emulsion mixtures for roads, PhD thesis, University of Nottingham, 1996.

[12] I. N. A. Thanaya, Improving the performance of cold bituminous emulsion mixtures (CBEMs): incorporating waste, PhD thesis, University of Leeds, 2003.

[13] L. Cheng, Developing Evaluation Method of Moisture Susceptibility for Cold Mix Asphalt, University of Wisconsin - Madison, 2013.

[14] H. A. Khalid and O. K. Monney, Moisture damage potential of cold asphalt, Int J Pavement Eng (2009) 10: 311-318. https://doi.org/10.1080/10298430802169838

[15] F. Olard, C. L. Noan, E. Bedunean, A. Romier, Low energy asphalts for sustainable road construction, Proc. 4th Eurasphalt and Eurobitume Congress, 2008, 21-23.

[16] M. N. Partl, Sustainable development through asphalt recycling in Switzerland, in International Workshop ISAP Technical Committee APE Asphalt Pavements and Environment, 2010

[17] A. D. James, D. Needham, P. S. F. Brown, The benefits of using Ordinary Portland Cement in solvent free dense graded bituminous emulsion mixtures, Proc Int Symposium on Asphalt Technology, 1996.

[18] I. E. A. Thanaya, S. E. Zoorob, J. P. Forth, A laboratory study on coldmix, cold-lay emulsion mixtures, Proc. ICE - Transport (2009) 1: 4755. https://doi.org/10.1680/tran.2009.162.1.47

[19] S. F. Brown, D. Needham, A Study of Cement Modified Bitumen Emulsion Mixtures, Proc Association of Asphalt Paving Technologists, 2000, 1-22.

[20] A. García, P. Lura, M. N. Partl, I. Jerjen, Influence of cement content and environmental humidity on asphalt emulsion and cement composites performance, Mater Struct (2012) 46: 1275-1289. https://doi.org/10.1617/s11527-012-9971-6

[21] G. Li, Y. Zhao, S.-S. Pang, W. Huang, Experimental study of cementasphalt emulsion composite, Cem Concr Res (1998) 28: 635-641. https://doi.org/10.1016/S0008-8846(98)00038-6

[22] S. Oruc, F. Celik, M. V. Akpinar, Effect of cement on emulsified asphalt mixtures, J Mater Eng Perform (2007) 16: 578-583. https://doi.org/10.1007/s11665-007-9095-2

[23] R. J. Schmidt, L. E. Santucci, L. D. Coyne, Performance characteristics of cement modified asphalt emulsion mixes, Proc Association of Asphalt Paving Technologists, 1973, 300-319.

[24] M. Bocci, A. Grilli, F. Cardone, A. Graziani, A study on the mechanical behaviour of cement-bitumen treated materials, Constr Build Mater (2011) 25: 773-778. https://doi.org/10.1016/j.conbuildmat.2010.07.007

[25] Y. Harada, S. Tottori, N. Itai, T. Noto, Development of cementasphalt mortar for slab tracks in cold climate, 1983.

[26] F. Wang, Z. Liu, T. Wang, and S. Hu, A novel method to evaluate the setting process of cement and asphalt emulsion in CA mortar, Mater Struct (2008) 41: 643-647. https://doi.org/10.1617/s11527-007-9270-9

[27] N. Pouliot, J. Marchand, M. Pigeon, Hydration Mechanisms, Microstructure, and Mechanical Properties of Mortars Prepared with Mixed Binder Cement Slurry-Asphalt Emulsion, J Mater Civ Eng (2003) 15: 54-59. https://doi.org/10.1061/(ASCE)0899-1561(2003)15:1(54)

[28] F. Wang, Z. Liu, S. Hu, Early age volume change of cement asphalt mortar in the presence of aluminum powder, Mater Struct (2010) 43: 493-498. https://doi.org/10.1617/s11527-009-9505-z
[29] F. Wang, Y. Liu, S. Hu, Effect of early cement hydration on the chemical stability of asphalt emulsion, Constr Build Mater (2013) 42: 146-151. https://doi.org/10.1016/j.conbuildmat.2013.01.009

[30] L. China Railway Eight Bureau Group Co., Cement asphalt mortar and its preparing method. Patent, China, 2006.

[31] China Petroleum \& Chemical Corporation, Emulsified asphalt cement mortar for CRTS I-type slab ballastless track and preparation method. Patent, China, 2013.

[32] D. R. Salomon, Asphalt emulsion technology. Transportation Research Board, Washington, DC, 2006.

[33] R. L. Terrel, C. K. Wang, Early curing behaviour of cement modified asphalt emulsion mixtures-AAPT report, Proc Association of Asphalt Paving Technologists, 1971, 108-125.

[34] A. Al-Hdabi, H. Al Nageim, L. Seton, Performance of gap graded cold asphalt containing cement treated filler, Constr Build Mater (2014) 69: 362-369. https://doi.org/10.1016/j.conbuildmat.2014.07.081

[35] T. Rutherford, Z. Wang, X. Shu, B. Huang, D. Clarke, Laboratory investigation into mechanical properties of cement emulsified asphalt mortar, Constr Build Mater (2014) 65: 76-83. https://doi.org/10.1016/j.conbuildmat.2014.04.113

[36] B. Gómez-Meijide, I. Pérez, Effects of the use of construction and demolition waste aggregates in cold asphalt mixtures, Constr Build Mater (2014) 51: 267-277. https://doi.org/10.1016/j.conbuildmat.2013.10.096

[37] F. Cardone, A. Grilli, M. Bocci, A. Graziani, Curing and temperature sensitivity of cement - bitumen treated materials, Int J Pavement Eng (2014) 16: 868-880. https://doi.org/10.1080/10298436.2014.966710

[38] D. Swiertz, P. Johannes, L. Tashman, H. Bahia, Evaluation of laboratory coating and compaction procedures for cold mix asphalt, J Assoc Asph Paving Technol (2012) 81: 81-107.

[39] A. W. Hefer, Adhesion in bitumen-aggregate systems and quantification of the effects of water on the adhesive bond, PhD Thesis, Texas A\&M University, 2004.

[40] X. Fang, F. Winnefeld, P. Lura, Precipitation of anionic emulsifier with ordinary Portland cement, J Colloid Interface Sci (2016) 479: 98-105. https://doi.org/10.1016/j.jcis.2016.06.042

[41] X. Fang, A. Garcia-hernandez, F. Winnefeld, P. Lura, Influence of Cement on Rheology and Stability of Rosin Emulsified Anionic Bitumen Emulsion, J Mater Civ Eng (2015) 28: 04015199. https://doi.org/10.1061/(ASCE)MT.1943-5533.0001454

[42] J. Ouyang and Y. Tan, Rheology of fresh cement asphalt emulsion pastes, Constr Build Mater (2015) 80: 236-243. https://doi.org/10.1016/i.conbuildmat.2015.01.078

[43] J. Ouyang, Y. Tan, D. J. Corr, S. P. Shah, Investigation on the Mixing Stability of Asphalt Emulsion with Cement through Viscosity, 2015, 1-8.

[44] L. Boucard, V. Schmitt, F. Farcas, V. Gaudefroy, Bitumen emulsions formulation and destabilisation process relationship: influence of salts addition, Road Mater Pavement Des (2015) 16: 330-348. https://doi.org/10.1080/14680629.2015.1030910

[45] R. W. Head, An Informal Report of Cold Mix Research Using Emulsified Asphalt as a Binder, Proc Association of Asphalt Paving Technologists, 1974, 110-131.

[46] X. Fang, A Fundamental research on cold mix asphalt modified with cementitious materials, PhD Thesis, ETH Zurich, 2016.

[47] M. Miljković, M. Radenberg, X. Fang, P. Lura, Influence of emulsifier content on cement hydration and mechanical performance of bitumen emulsion mortar, Mater Struct (2017)

[48] J. S. Damtoft, J. Lukasik, D. Herfort, D. Sorrentino, E. M. Gartner, Sustainable development and climate change initiatives, Cem Concr Res (2008) 38: 115-127. https://doi.org/10.1016/j.cemconres.2007.09.008

[49] Q. Wang, P. Yan, A. Ruhan, J. Yang, X. Kong, Strength Mechanism of Cement-Asphalt Mortar, J Mater Civ Eng (2011) 23: 1353-1359. https://doi.org/10.1061/(ASCE)MT.1943-5533.0000301

[50] Z. Wang, X. Shu, T. Rutherford, B. Huang, D. Clarke, Effects of asphalt emulsion on properties of fresh cement emulsified asphalt mortar, Constr Build Mater (2015) 75: 25-30. https://doi.org/10.1016/j.conbuildmat.2014.11.013

[51] L. D. Poulikakos, M. N. Partl, Investigation of porous asphalt microstructure using optical and electron microscopy, J Microsc (2010) 240: 145-154. https://doi.org/10.1111/j.1365-2818.2010.03388.x

[52] J. P. Zaniewski, Y. Yan, Hot Mix Asphalt Concrete Density, Bulk Specific Gravity, and Permeability, Report, Asphalt Technology Program, Department of Civil and Environmental Engineering, West Virginia University, 2012. 